\title{
Statyba
}

\section{INVESTIGATIONS INTO PROPERTIES OF MINERAL WOOL SLABS OF INCREASED STIFFNESS MANUFACTURED OF A LARGE-SIZE BEAM}

\section{A. Šakmanas}

To cite this article: A. Šakmanas (1997) INVESTIGATIONS INTO PROPERTIES OF MINERAL WOOL SLABS OF INCREASED STIFFNESS MANUFACTURED OF A LARGE-SIZE BEAM, Statyba, 3:11, 57-60, DOI: 10.1080/13921525.1997.10531354

To link to this article: https://doi.org/10.1080/13921525.1997.10531354

曲 Published online: 26 Jul 2012.

Submit your article to this journal $₫$

Џ Article views: 37 


\section{PADIDINTO STANIUUMO MINERALINÉS VATOS PLOKŠČIU, PAGAMINTU IS̆ SUFORMUOTO STAMBIŲ GABARITU MASYVO, SAVYBßES}

\section{A. Šakmanas}

\section{Ivadas}

Padidinto standumo mineralinès (akmens) vatos plokštès daugiausia naudojamos plokštiems stogams šiltinti. Todel tokioms plokštèms, be gerų termoizoliaciniu savybiu, keliamas dar papildomas reikalavimas - atsparumas gniıždymui. Jo pasiekiama didinant vidutinị tanki (tūrio masẹ). Tai susiję su didesnèmis žaliavy ir energijos sąnaudomis. Be to, i aplinką išmetama daugiau teršaly produkcijos vienetui. Sparčiai augant žaliavy ir ypač energijos kainoms buvo ieškoma būdų, kaip šias sąnaudas mažinti. Tuo tikslu remiantis išradimu [1] buvo sukurtas ir išbandytas naujas padidinto standumo mineralinès vatos iš dalies orientuoto plaušo plokščių (toliau tekste - plokščił) gamybos būdas [2]. Jo esmé - plokščių vidutinio tankio mažinimas išlaikant nepakitusi jų atsparumą gniuždymui. Naudojant ši būdą yra galimybé gaminti taip pat ir nestandartiniu gabaritu plokštes, ypač reikalingas stogų dangoms bei sienoms šiltinti. Kartu buvo siekiama didinti plokščių atsparumą gniuždymui, mažinti encrgijos ir žaliavų sąnaudas bei kenksmingu atliekų kickị.

Plokščiy gamybos ịrangą sudaré terminio apdorojimo agregatas, kuriame laboratorijos sąlygomis iš rišikliais išpurkšto mineralinès vatos kilimo buvo formuojamas ir termiškai apdorojamas $B=1 \mathrm{~m}$ pločio ir $I I=0,5 \mathrm{~m}$ storio masyvas. Po terminio apdorojimo pastarasis buvo pjaustomas i $L=1 \mathrm{~m}$ ilgio gabalus, iš kuriụ išilginio pjovimo būdu buvo gaminamos plokštés. Perstatant pjūklus atsirado galimybès masyvo pjaustymo i plokštes staklèmis (agregatu) gaminti ịairaus storio $\delta$ (taip pat ir nestandartiniu storiu) plokštes.

Kadangi naujasis plokščiu gamybos būdas neǔ̌tikrino tolygaus plaušl pasiskirstymo, lieka neaišku, kick tai gali turéti ịtakos plokščił kokybci ir apskritai ar tokios plokštes atitinka savo paskirtị. I šiuos klausimus [2] nebuvo atsakyta.

\section{Tyrimų tikslas}

Šio darbo tikslas - išlirti padidinto standumo mineralines vatos plokščil, pagamintu iš suformuoto stambių gabarilu masyvo, savybes (plaušu pasiskirstymo tolygumą plokšteje, atsparumą gniuždymui, laidumą šilumai, rišiklių polikondensacijos užbaigtumą) ir remiantis tyrimı̨ rezultatais atsakyti klausimą, ar minètu būdu pagamintos plokštès atitinka savo paskirti.

\section{Tyrimo metodas}

Plaušy masès pasiskirstymo netolygumas buvo tiriamas tick ties skersiniu masyvo pjüviu, tiek pagamintose ploks̀icse. Pirmuoju atveju buvo išpjaunami $\delta=120 \mathrm{~mm}$ storio bandiniai (gabaritai $1000 \times 500 \times 120 \mathrm{~mm}$ ). Pastaricji savo ruožtu, kaip parodyta 1 pav. schema, buvo pjaustomi i gretasicnius, kuriy vidutinis tankis buvo nustatomas juos sveriant ir matuojant tūrị. Analogiškai buvo elgiamasi su plokštémis, kuriy storis $\dot{\partial}$ perstatant pjūklus buvo keičiamas nuo $60 \mathrm{iki} 120 \mathrm{~mm}$.

Plaušų masćs pasiskirstymo netolygumas ivertintas santykiniais dydžiais: $K_{\| l}$ - horizontaliuju bei $K_{V}$ vertikaliujų sluoksnių. Minċti dydžiai - tai santykiai:

$$
\begin{aligned}
& K_{H}=\left(\gamma_{j}-\gamma_{m}\right) / \gamma_{m}, \\
& K_{V}=\left(\gamma_{i}-\gamma_{m}\right) / \gamma_{m} .
\end{aligned}
$$

Čia $\gamma_{m}$ - iš masyvo išpjauto bandinio (toliau tekste bandinio) arba plokštès vidutinis tankis, randamas juos pasveriant ir išmatuojant 1 ūrị, $\mathrm{kg} / \mathrm{m}^{3}$; $\gamma_{t}=\sum_{j=1}^{m} \gamma_{i-j} / m-$ vertikaliojo $i$-ojo sluoksnio 


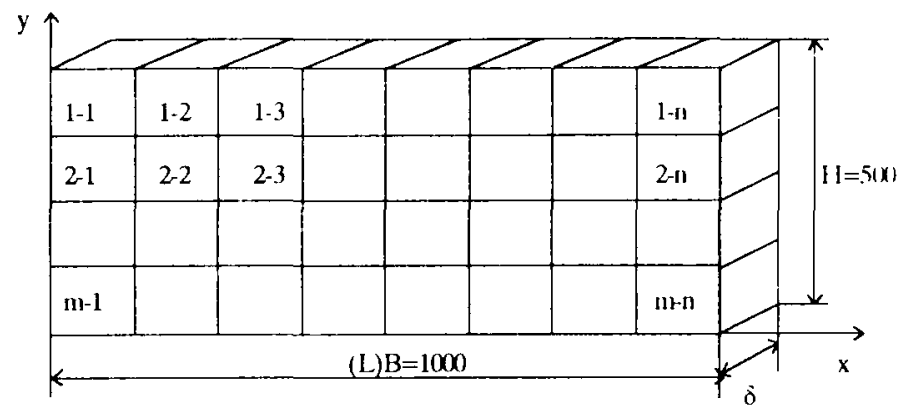

1 pav. Bandinio arba plokštés pjaustymo i gretasienius schema plaušly mases pasiskirstymo netolygumui tirti

Fig 1. Scheme of beam sample (or slab) cutting into parallelepipeds for investigation of bulk density distribution in it

vidutinis tankis $\mathrm{kg} / \mathrm{m}^{3} ; \quad \gamma_{j}=\sum_{i=1}^{n} \gamma_{i-j} / n$ - horizontaliojo $j$-ojo sluoksnio vidutinis tankis $\mathrm{kg} / \mathrm{m}^{3} ; n$ vertikaliuju sluoksnių skaičius, $m$ - horizontaliujų sluoksniy skaicius.

Tyrimo rezultatai apibendrinti grafiškai parodant, kaip $K_{H}$ kinta pagal bedimensinę koordinatę $y / H$, o $K_{V}$ - pagal $x / B$ bandiniui bei $x / L$ plokštėms (mūsų atveju $B=L$ ). Čia $x$ ir $y$ - koordinačių ašys: $x$ sutapatinta su dydžiais $B$ arba $L, y$ - su $H$ (1 pav.).

Plokščiu atsparumas gniuždymui, kai santykinè deformacija siekia $10 \%$, šilumos laidumo koeficientas bei rišiklių polikondensacijos užbaigtumas buvo nustatomi naudojantis atitinkamų standartu reglamentuota metodika.

\section{Tyrimu rezultatai ir ju aptarimas}

Dydžio $K_{H}$ kitimas tiek masyvo skerspjūryje, tiek plokštėse (2a pav.) rodo, kaip ir buvo tikimasi, didžiausią masés susikaupimą apatiniuose sluoksniuose. Iš dydžio $K_{V}$ kitimo matyti, kad vertikaliuo- siuose masyvo sluoksniuose didð̌iausia plaušt̨ masè dẻl masyvo formavimo ypatumy susikaupusi pagal masyvo kontūrus (2b pav.). Kaip matyti, abiem atvejais esama išimčill, kurilı pagrindinè priežastis rankinis masyvo formavimo irenginio pripildymo būdas bei kilimo deformacija jị gabenant iš gamyklos ị laboratoriją (tokios buvo bandymo sąlygos).

Plokščì atsparumo gniuždymui, kai santykinè deformacija siekia $10 \%$, bandymo rezultatai ịvairiuose bandiniuose pavaizduoti 3 pav. Čia matyti, kad nagrinèjamu būdu pagamintu plokščit atsparumas padidèja iki 2 kartų lyginant su reikšmèmis, reglamentuojamomis pagal standarta GOST 9573-82 П200 markès plokštėms. Didesnis atsparumas pasiekiamas didejant rišikliy kickiui (standarto ribose). Be to, reikalaujamą atsparumą, kaip matyti iš 3 pav., atlaiko mažesnio vidutinio tankio plokštés, t.y. $\gamma_{m}<175 \mathrm{~kg} / \mathrm{m}^{3}$, kurioms pagal standartą atsparumas gniuždymui nereglamentuojamas. Taigi mūsų gautas plaušų masés pasiskirstymo netolygumas plokštèje esminès ịtakos gniuždymo atsparumui neturi.

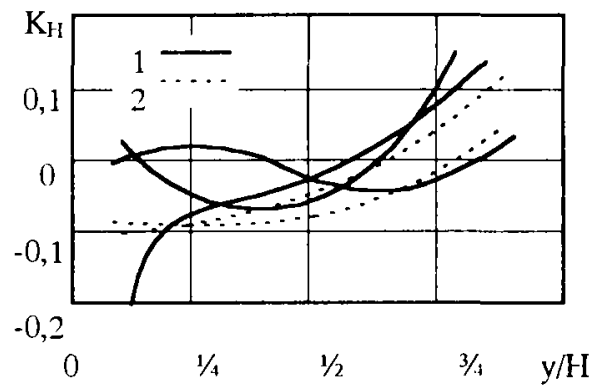

b

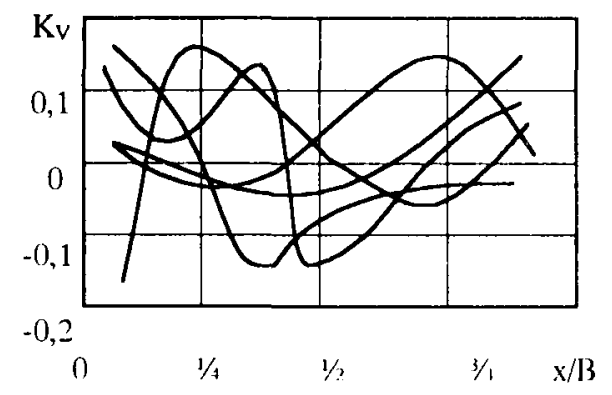

2 pav. Dydžių $K_{H}$ ir $K_{V}$ kitimas: a - pagal masyvo storị (plokštes plotị) $I /$ (1 - masyve, 2 - plokšstese); b - pagal masyvo plotị $B$

Fig 2. Variation of values $K_{H}$ and $K_{l}:$ a - vs the beam thickness or slab widh $/ /$ (1 - beam, 2 - slabs); b - vs the beam width $B$ 


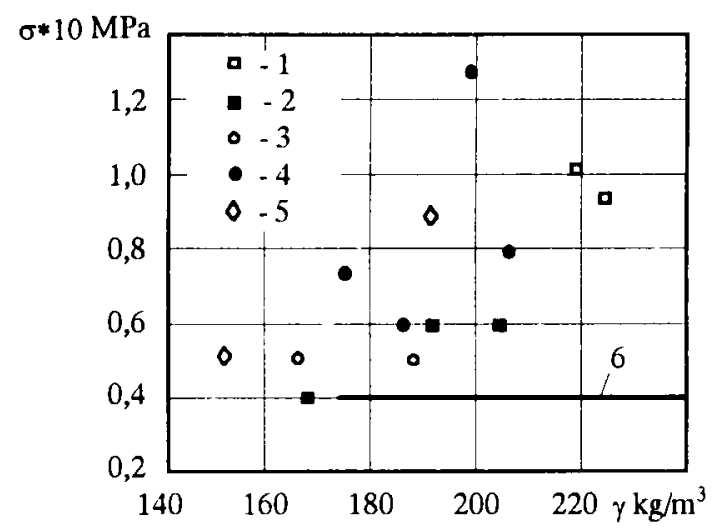

3 pav. Bandymo rezultaty̨ $\sigma$ palyginimas su standarto reglamentuojana reikšme (6) esant ivvairiems rišiklių kiekiams: $1-4,3 \% ; 2-5,0 \% ; 3-5,6 \%$; $4-6,5 \% ; 5-7,0 \%$

Fig 3. Comparison of experimental data $\sigma$ with standard value (solid line). Binders content in \%: 1 $4.3 \% ; 2-5.0 \% ; 3-5.6 \% ; 4-6.5 \% ; 5-7.0 \%$

Tačiau dèl vertikaliai orientuotų plaušų masès padidejjimo mažejja plokštẻs atsparumas lenkimui, t.y. jos gali lengvai lūžti tiek nuo nedidelio smūgio (stuktelejimo), tiek veikiamos nuosavo svorio. Tai sudaro tam tikrų nepatogumų jas vežant, perkeliant bei montuojant konstrukcijas. Šị ju trūkumą galima kompensuoti apklijuojant abi plokštès puses standžia medžiaga (kartonu, ruberoidu ir pan.).

Plokščių šilumos laidumo tyrimai parodè, kad daugumoje tirtų plokščiu koeficientu $\lambda$ reikšmès truputi padideja (iki 5\%), lyginant su GOST 9573-82 reglamentuojamomis maksimaliai leistinomis ju reikšmẻmis atitinkamų markių plokštèms (4 pav.). Tai aiškinama plaušų pasiskirstymo plokštèje struktūros pasikeitimu, t.y. vertikaliai orientuotų plaušų masès padidèjimu.

Rišiklių polikondensacijos užbaigtumo tyrimų rezultatai parodé, kad kai kuriose vietose rišiklių kiekis svyravo nuo $4 \%$ iki $7 \%$ pagal masę, o polikondensacijos laipsnis viršijo $99,3 \%$, kas visiškai patvirtino [2] padarytas išvadas.

\section{Išvados}

1. Iš suformuoto stambių gabaritul mineralinès vatos masyvo galima pagaminti tiek standartinių matmenų, tiek ir nestandartinių plokščių, kurių optimalus storis gali svyruoti nuo $60 \mathrm{iki} 500 \mathrm{~mm}$, kas leidžia geriausiai tenkinti ịvairił̨ statybinių konstrukcijų izoliacijos terminès varžos reikalavimus, ypač šiltinant plokščius stogus.

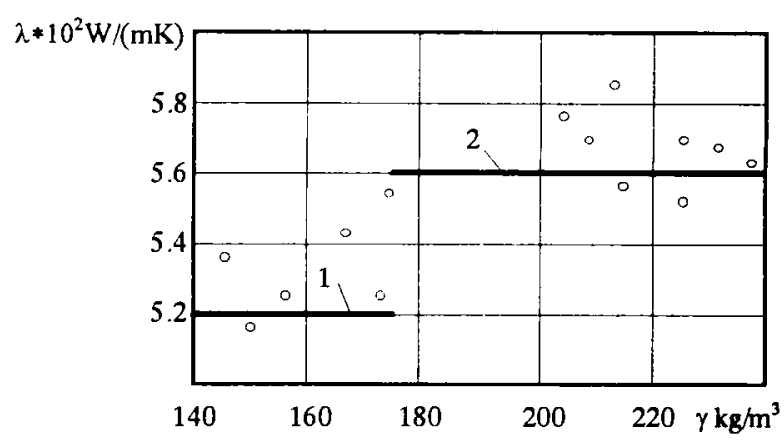

4 pav. Koeficienty $\lambda$ palyginimas su maksimaliai leistinomis jų reikšmèmis: 1 - plokštèms $\Pi 175 ; 2$ - plokštèms $\Pi 200$

Fig 4. Comparison of experimental data $\lambda$ with maximally admitted ones: 1 - slabs $\Pi 175$; 2 - slabs $\Pi 200$

\section{Pagamintos plokštès pagal rišikliu pasiskirstymą} bei jų polikondensacijos laipsni visiškai tenkina standartų reikalavimus.

3. Atsparumo gniuždymui padidèjimas igalina plokštèse apie du kartus sumažinti žaliavų, rišikliu bei energijos sąnaudas, taip pat išmetamų teršalu kiekius jų gamybos metu.

4. Pagamintų plokščių vidutinio tankio pasiskirstymo netolygumas svyruoja $\pm 20 \%$. Bandant minètą agregatą veikiančiose technologinèse linijose, šis netolygumas pagerejus masyvo formavimo sąlygoms sumažètų.

Dèl plaušų pasiskirstymo struktūros pasikeitimo šiek tiek (iki 5\%) padidèja plokščių šilumos laidumo koeficientas lyginant su maksimaliai leistina standartine jo reikšme, taip pat sumažeja atsparumas lenkimui net veikiant nuosavam svoriui. Todè pagamintas plokštes iš abiejų pusių būtina apklijuoti standžia medžiaga.

\section{Literatūra}

1. А.c. 1134554 (СССР), МКИ СО 3В 37/14. Устройство для тепловой обработки волокнистого материала / Н.Ю. Вегите, К.Я. Паулёнис, И.С. Йочис и др. / Б.И. № 2, 1985

2. К.Я. Паулёнис, А.Ю. Скринска. Новый способ производства минераловатных плит повышенной жесткости с ориентированным волокном // Строительные материалы, 6, 1989, с. 9.

Itteikta 19970319 


\section{INVESTIGATIONS INTO PROPERTIES OF MINERAL WOOL SIABS OF INCREASED STIFFNESS MANUFACTURED OF A LARGE - SIZE BEAM}

\section{A. Šakmanas}

Sum mary

The article presents the results of experimental investigations into non-uniformity of bulk density distribution, compressive strength, heat conductivity, and completion of binders polycondensation in slabs manufactured from a large-size mineral wool beam (its width $B=1000 \mathrm{~mm}$ and thickness $H=500 \mathrm{~mm}$ ).

The non-uniformity of bulk density was investigated as in a beam (for this purpose from different places of a beam there were cut samples with a thickness $d=120 \mathrm{~mm}$ ), as in slabs (their length $L=1000 \mathrm{~mm}$ and width $H=500$ $\mathrm{mm})$. For such a purpose samples or slabs were cut after scheme (Fig 1) determining bulk density of each paralellepiped $g_{i j .}$. The non-uniformity of bulk density was evaluated by values $K_{H}$ and $K_{\mathrm{V}}$, representing a relative departure from beam or slab bulk density $g_{m}$. These values were calculated after formulae (1) and (2) where $g_{i}$ is the $\mathrm{i}$-th vertical layer bulk thickness; $g_{j}$ is the $\mathrm{j}$-th horizontal layer bulk thickness, $n$ is number of vertical layers, $m$ is number of horizontal layers. Variation of values $K_{H}$ and $K_{v^{\prime}}$ shows that relative departure from slab or beam bulk density does not exceed $\pm 20 \%$ (Fig 2).
Comparing our experimental data with standard GOST 9573-82 requirements, one can sec that compressive strength values of slabs $s$ can exceed the standard one up to two times without increasing their bulk density (Fig 3). Better results are obtained when the content of binders is greater (within standard requirements). Also, it is possible to see that heat conductivity $l$ because of structural changes of fibres distribution in a slab slightly increases (not more than $5 \%$ ), when we are comparing this heat conductivity value with a maximally admitted standard one (Fig 4).

Employment of this method allows the production of slabs, the optimal thickness of which has the ability to change from 6 to $500 \mathrm{~mm}$. The binders polycondensation in such slabs is fully completed. Such slabs are suitable for insulating flat roofs, but their stiffness must be fastened by glueing them with stiff material.

Aloyzas ŠAKMANAS. Doctor, Associate Professor. Department of Heating and Ventilation. Vilnius Gediminas Technical University (VGTU), 11 Saulėtekio Ave, 2040 Vilnius, Lithuania.

Doctor's degree (theoretical fundamentals of thermotechnics) in 1979 at the Institute of Physical and Technical Problems of Power Engineering of Lithuanian Academy of Sciences. Author of 16 scientific articles. Research interests: fundamentals of heat transfer, thermotechnical processes in technology of building materials, energy saving. 